\title{
Necdin Controls Foxol Acetylation in Hypothalamic Arcuate Neurons to Modulate the Thyroid Axis
}

\author{
Koichi Hasegawa, ${ }^{1}$ Tomohiro Kawahara, ${ }^{1}$ Kazushiro Fujiwara, ${ }^{1}$ Mayumi Shimpuku, ${ }^{2}$ Tsutomu Sasaki, ${ }^{2}$ \\ Tadahiro Kitamura, ${ }^{2}$ and Kazuaki Yoshikawa ${ }^{1}$ \\ ${ }^{1}$ Laboratory of Regulation of Neuronal Development, Institute for Protein Research, Osaka University, Suita, Osaka 565-0871, Japan, and ${ }^{2}$ Metabolic Signal \\ Research Center, Institute for Molecular and Cellular Regulation, Gunma University, Maebashi, Gunma 371-8512, Japan
}

The forkhead transcription factor Foxol regulates energy homeostasis by modulating gene expression in the hypothalamus. Foxo1 undergoes post-translational modifications such as phosphorylation and acetylation, which modulate its functional activities. Sirtuin 1 (Sirt1), a nicotinamide adenine dinucleotide-dependent protein deacetylase, regulates the acetylation status of Foxo1 in mammalian cells. Necdin, a pleiotropic protein required for neuronal development and survival, interacts with both Sirt1 and p53 to facilitate p53 deacetylation. The necdin gene $(\mathrm{Ndn})$, an imprinted gene transcribed only from the paternal allele, is strongly expressed in hypothalamic neurons. Here, we demonstrate that necdin controls the acetylation status of Foxol in vivo in hypothalamic arcuate neurons to modulate the thyroid function. Necdin forms a stable ternary complex with Sirtl and Foxol, diminishes Foxol acetylation, and suppresses the transcriptional activity of Foxol in vitro. Paternal $N d n$ mutant mice express high levels of acetylated Foxo1 and mRNAs encoding agouti-related protein and neuropeptide $\mathrm{Y}$ in the hypothalamus in vivo during the juvenile period. The mutant mice exhibit endocrine dysfunction characteristic of hypothalamic hypothyroidism. Chemically induced hyperthyroidism and hypothyroidism lead to hypothalamic responses similar to those under necdin-deficient and excessive conditions, respectively, suggesting that thyroid hormone serves as a negative regulator of this system. These results suggest that necdin regulates Foxol acetylation and neuropeptide gene expression in the arcuate neurons to modulate the hypothalamic-pituitary-thyroid axis during development.

\section{Introduction}

The hypothalamus plays a pivotal role in the integration of central and peripheral signals that regulate energy homeostasis. In the hypothalamic arcuate nucleus (ARC), neurons that synthesize neuropeptides such as agouti-related protein (AGRP), neuropeptide Y (NPY), and proopiomelanocortin (POMC) project their axons to adjacent orexigenic and anorexic neurons (Barsh and Schwartz, 2002). These neurons also regulate the activities of neurons expressing thyrotropin-releasing hormone (TRH) to modulate the function of the hypothalamic-pituitary-thyroid (HPT) axis (Lechan and Fekete, 2006). Thus, these hypothalamic ARC neurons control the balance between food intake and energy expenditure.

Forkhead transcription factors of the Foxo subfamily (Foxos) regulate energy homeostasis in various organs and tissues (Accili and Arden, 2004). In mammalian cells, Foxos are phosphorylated

Received Jan. 11, 2012; revised Feb. 21, 2012; accepted Feb. 29, 2012.

Author contributions: K.H., T. Kitamura, and K.Y. designed research; K.H., T. Kawahara, K.F., M.S., and T.S. performed research; K.H. and K.Y. wrote the paper.

This study was supported by Grants-in-Aid for Scientific Research B2 (21300138; to K.Y.) and Young Scientists B (23700445; to K.H.) from the Japan Society for the Promotion of Science. Metabolic monitoring experiments were performed under the joint research program (11016) of the Institute for Molecular and Cellular Regulation, Gunma University. We thank Ms. K. Imada for technical support, Ms. C. Shiraishi for animal maintenance, and Dr. A. Fukamizu for research materials.

The authors declare no competing financial interests.

Correspondence should be addressed to Kazuaki Yoshikawa, Institute for Protein Research, 0saka University, 3-2 Yamadaoka, Suita, 0saka 565-0871, Japan. E-mail: yoshikaw@protein.osaka-u.ac.jp.

DOI:10.1523/JNEUROSCI.0142-12.2012

Copyright $\odot 2012$ the authors $\quad 0270-6474 / 12 / 325562-11 \$ 15.00 / 0$ through insulin-dependent activation of AKT/protein kinase B, which induces rapid nuclear exclusion of Foxos to inhibit their transcriptional activities (van der Horst and Burgering, 2007). Foxos are also acetylated by histone acetyltransferases such as p300 and the CREB-binding protein (CBP), and their acetylation states are regulated by sirtuin 1 (Sirt1), a mammalian nicotinamide adenine dinucleotide-dependent histone deacetylase involved in the regulation of energy homeostasis and lifespan extension (Accili and Arden, 2004; Haigis and Sinclair, 2010). In hypothalamic neurons, Foxol controls transcription of Agrp and Npy genes in the ARC to modulate food intake (Kim et al., 2006; Kitamura et al., 2006). However, little is known about the mechanism that regulates the acetylation status of hypothalamic Foxo 1 and its functional consequences in energy homeostasis.

Necdin is a multifunctional protein that promotes differentiation and survival of mammalian neurons (Maruyama et al., 1991; Kuwako et al., 2005; Kuwajima et al., 2006). The human necdin gene $N d n$ is mapped to chromosome 15q11-q13, a region deleted in the Prader-Willi syndrome (PWS) (Jay et al., 1997; MacDonald and Wevrick, 1997). PWS is a classic genomic imprinting-associated neurodevelopmental disorder whose major symptoms, such as hyperphagia, short stature, and hypogonadism, are thought to be the results of hypothalamic dysfunction. Furthermore, mouse $N d n$ is strongly expressed in the hypothalamus (Aizawa et al., 1992; Uetsuki et al., 1996), in which only the paternal $N d n$ allele is transcribed through genomic imprinting, a placental mammal-specific epigenetic mechanism (MacDonald and Wevrick, 1997; Gérard et al., 1999; Muscatelli et 
al., 2000; Kuwako et al., 2005). We have previously found that necdin forms a stable complex with both Sirt1 and p53 to facilitate p53 deacetylation in cortical neurons (Hasegawa and Yoshikawa, 2008). These findings prompted us to investigate whether necdin controls hypothalamic Foxol acetylation via Sirtl and modulates the activities of hypothalamic neurons involved in energy homeostasis during hypothalamic development.

The present study provides evidence that necdin forms a stable complex with Foxol and Sirt1 to promote Foxo1 deacetylation and reduce its transcriptional activity. We also demonstrate that paternal $N d n$ mutant mice have high levels of acetylated Foxol and AGRP/NPY expression in the ARC neurons and exhibit endocrine abnormalities due to dysfunction of the HPT axis during the juvenile period.

\section{Materials and Methods}

Animals. $\mathrm{Ndn}$ knock-out mice $\left(\mathrm{Nd} n^{t m l K y}\right)$ were generated and maintained as described previously (Kuwako et al., 2005). Heterozygous male mice $\left(\mathrm{Ndn} n^{+-}\right)(>20$ generations on the ICR background) were crossed with wild-type $\left(\mathrm{Ndn} n^{+/+}\right)$female mice to obtain $\mathrm{Ndn} n^{+/+}$and paternal $N d n$-deficient $\left(N d n^{+\mathrm{m} /-\mathrm{p}}\right)$ siblings. Genotypes were analyzed by PCR for mutated $N d n$ locus. Male mice at postnatal day 28 (P28) and P34 were housed in a temperature- and humidity-regulated room with $12 \mathrm{~h} \mathrm{light/}$ dark cycle (light on at 8:00 A.M.) and were fed ad libitum normal diet pellets (D12450B; Research Diets). Experiments using gene-targeted mice were approved by the Recombinant DNA and Animal Experiment Committees of the Institute for Protein Research, Osaka University, and were performed in accordance with institutional guidelines and regulations.

Western blotting. Tissues were prepared from male ICR mice at P30. Hypothalamic nuclei were prepared as described previously (Dryden et al., 1996). Briefly, a fresh brain was dissected between the middle of the optic chiasm and mammillary bodies to obtain a hypothalamic block, and $500 \mu \mathrm{m}$ slices of the block were made using a soft tissue slicer (PRO7; DOSAKA EM Co.). The hypothalamic nuclei were dissected using a tungsten needle. Proteins in tissue lysates ( $10 \mu \mathrm{g} / \mathrm{lane})$ were separated by $10 \%$ SDS-PAGE, blotted, and detected with antibodies against Foxo1 (FKHR H-128; 1:100; Santa Cruz Biotechnology), necdin (NC243; 1:3000) (Niinobe et al., 2000), Sirt1 (07-131; 1:500; Merck Millipore), $\gamma$-tubulin (GTU-88; 1:1000; Sigma-Aldrich), acetylated Foxo1 (AcFKHR D-19; 1:100; Santa Cruz Biotechnology), $\beta$-tubulin (TUB2.1; 1:1000; Sigma-Aldrich), and TRH (11170; 1:100; MP Biochemicals). Signal intensities were quantified with an image analyzer (LAS-1000 Plus; Fuji Film) and Image 1.44 software.

Immunohistochemistry. Immunohistochemistry was performed as described previously (Sasaki et al., 2010). Briefly, mice were transcardially perfused with $0.9 \% \mathrm{NaCl}$ followed by $4 \%$ paraformaldehyde solution in $100 \mathrm{~mm}$ phosphate buffer, $\mathrm{pH}$ 7.4. Brains were cut into blocks containing the hypothalamus, fixed with the above solution overnight, and cryoprotected by immersion in 10,20, and $30 \%$ sucrose at $4^{\circ} \mathrm{C}$ for $24 \mathrm{~h}$ each. Frozen $12-\mu \mathrm{m}$-thick tissue sections were prepared, and coronal sections of $\mathrm{Ndn} n^{+/+}$and $\mathrm{Ndn} n^{+\mathrm{m} /-\mathrm{p}}$ mice were selected on the basis of morphological similarities judged from the ventricular shape. After treatment with $10 \mathrm{~mm}$ citric acid buffer, $\mathrm{pH} 6.0$, for $25 \mathrm{~min}$ at $85^{\circ} \mathrm{C}$ using a microwave processor (MI-77; Azumaya) for antigen retrieval, hypothalamic sections were incubated with primary antibodies at $4^{\circ} \mathrm{C}$ overnight, and then treated with fluorescence dye-conjugated secondary antibodies for $1 \mathrm{~h}$ at room temperature. Primary antibodies used are anti-necdin (GN1; 1:1000) (Kuwako et al., 2005), anti-Ac-FKHR (D-19; 1:200; Santa Cruz Biotechnology), rabbit anti-Sirt1 (07-131; 1:200; Merck Millipore), mouse anti-Sirt1 (ab50517; 1:200; Abcam), and guinea pig anti-Sirt1 (GS1; 1:100; raised against a purified recombinant protein of maltosebinding protein fused to Sirt1 amino acids 1-235). The secondary antibodies Alexa Fluor 488-conjugated anti-guinea pig and rabbit IgGs (1: 1000; Invitrogen); cyanine 3-conjugated anti-rabbit, guinea pig, and mouse IgGs (1:500; Jackson ImmunoResearch); and Alexa Fluor 350conjugated anti-rabbit IgG (1:500; Jackson ImmunoResearch). Chromo- somal DNA was detected with $3.3 \mu \mathrm{M}$ Hoechst 33342 (Sigma-Aldrich). The images were observed with fluorescence microscopes (LSM5 PASCAL; Zeiss; MZ16 F, Leica Microsystems) and were processed using Adobe Photoshop CS4 software.

Immunoprecipitation assay. cDNA encoding full-length mouse Foxol (Daitoku et al., 2004) were subcloned into $6 \mathrm{Myc}(\mathrm{N})-\mathrm{pcDNA} 3.1+$ for Myc tagging. HEK293A cells were transfected with expression vectors for Myc-Foxo1, necdin, and Sirt1-FLAG (Hasegawa and Yoshikawa, 2008) by the calcium phosphate method, and were harvested $24 \mathrm{~h}$ later and lysed in 10 mm Tris-HCl, pH 8.0, $150 \mathrm{~mm} \mathrm{NaCl}, 1$ mm EDTA, 1\% Nonidet P-40, 10\% glycerol, and protease inhibitors (Complete; Roche). Proteins $(200 \mu \mathrm{g})$ in the lysates were incubated at $4^{\circ} \mathrm{C}$ for $2 \mathrm{~h}$ with antibodies, pelleted with protein A-Sepharose (GE Healthcare), separated by $7.5 \%$ SDS-PAGE, and detected by Western blotting using antibodies to Myc (9E10; 1:10), necdin (NC243; 1:3000), and FLAG (M2; 1:500; SigmaAldrich), as described previously (Kuwajima et al., 2006). For detection of endogenous complex of necdin, Sirt1, and Foxol, proteins in hypothalamic lysates of P30 mice (1 mg) were incubated with GN1 (1:100) and GS1 (1:100) antibodies, pelleted with Dynabeads Protein A (Invitrogen), separated by $7.5 \%$ SDS-PAGE, and detected by Western blotting with antibodies against Foxol (FKHR H-128; 1:100; Santa Cruz Biotechnology), Sirt1 (07-131; 1:500; Merck Millipore), HDAC1 (a class I histone deacetylase) (C19; 1:200; Santa Cruz Biotechnology), and necdin (NC243; 1:3000). The protein concentration was determined by the Bradford method (Bio-Rad).

Reporter assay. HEK293A cells were plated in $35 \mathrm{~mm}$ dishes $\left(5 \times 10^{4}\right.$ cells/dish), cultured for $24 \mathrm{~h}$ in DMEM supplemented with $10 \%$ FBS, and then transfected with the luciferase reporter plasmid pGL3 containing three copies of the insulin response sequence (Daitoku et al., 2004), p3xFLAG-CMV10-Foxo 1, pRc/CMV-necdin, and/or Sirt1-pcDNA3.1+ by the calcium phosphate method. For Sirt1 knock-down experiment, HEK293A cells were transfected with Sirt1 siRNA (Hasegawa and Yoshikawa, 2008) or control siRNA (40 pmol) in combination with above plasmids. The total amount of plasmid DNA was adjusted by adding empty pcDNA3.1+ (Invitrogen). Transfected cells were incubated for $24 \mathrm{~h}$, and then luciferase activity was measured with a luminometer (Lumat LB9501; Berthold) using Dual-luciferase Reporter Assay System (Promega).

Fluorescence microphotometry. Hypothalamic sections were immunostained for acetylated Foxol. The immunoreactive intensities were measured by fluorescence photometry system as described previously (Takazaki et al., 2002). Briefly, immunostained images were captured with a CCD camera (CoolSNAP monochrome; Nippon Roper) as 12-bit digital monochrome images. Fluorescence intensity of acetylated Foxol in each area was analyzed using fluorescence image analysis software (Fluoroimage Cool V; Mitani). The background intensity of the equalsized adjacent area without positive signals was subtracted from the intensity of positive signal-containing area.

Chromatin immunoprecipitation. Chromatin immunoprecipitation (ChIP) assay was performed as described previously (Lee et al., 2006). Briefly, formaldehyde cross-linked hypothalamic mince was homogenized and sonicated to generate an average DNA size of $\sim 500 \mathrm{bp}$, and then were incubated with rabbit anti-FKHR (H-128; Santa Cruz Biotechnology), GN1, GS1, and preimmune IgG prebound to Dynabeads Protein A for $12 \mathrm{~h}$ at $4^{\circ} \mathrm{C}$. The immunoprecipitation complexes were reverse-cross-linked by heating for $12 \mathrm{~h}$ at $65^{\circ} \mathrm{C}$. Immunoprecipitated and input DNAs were treated with proteinase $\mathrm{K}$, precipitated with isopropyl alcohol, and resuspended in sterile water. PCR was performed using template DNA and the following primers: AGRP promoter (417 bp; forward, $5^{\prime}$-cctgaaagctttgtcctctg- $3^{\prime}$; reverse, $5^{\prime}$-gcagaacctagggatgggtc$3^{\prime}$ ); and $\beta$-actin promoter (105 bp; forward, $5^{\prime}$-gcttctttgcagctccttcgttg- $3^{\prime}$; reverse, $5^{\prime}$-ctttgcacatgccggagccgttgt- $\left.3^{\prime}\right)$.

Quantitative RT-PCR. The hypothalamus and its nuclei were dissected as described above. Total RNA was extracted from tissues with phenol and guanidine thiocyanate mixture (TRI reagent; Molecular Research Center), and cDNA was synthesized from total RNA ( $2 \mu \mathrm{g})$ using Transcriptor First Strand cDNA Synthesis Kit (Roche Diagnostics). cDNA (10 ng) was used as templates for PCR. Primers used for real-time PCR are as follows: AGRP (forward, 5' -tggcctcaagaagacaactg-3'; reverse, 5' ${ }^{\prime}$-cattg- 
A

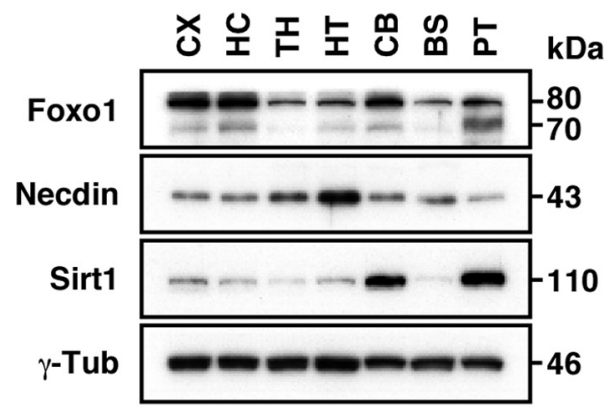

B

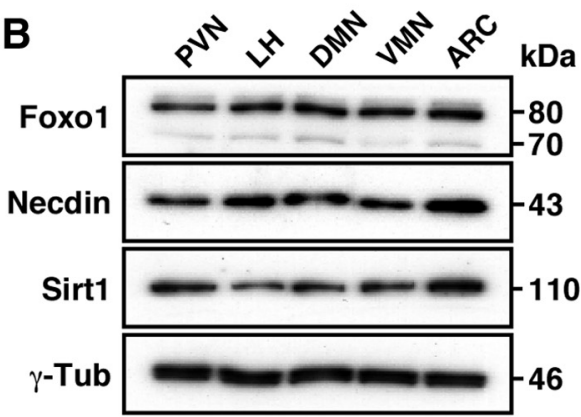

D
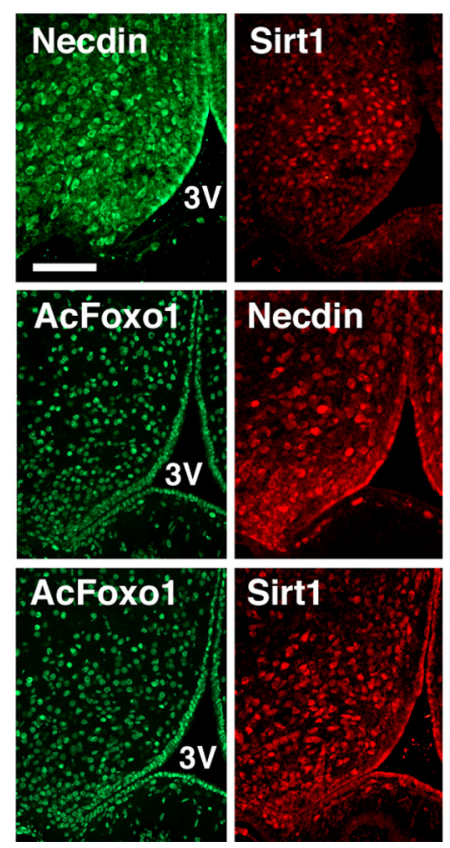

C
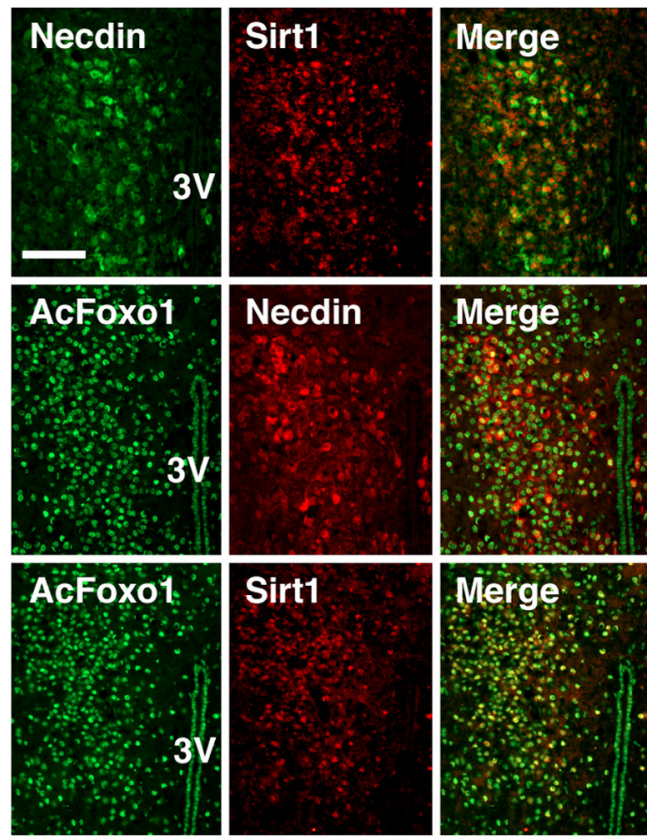

E
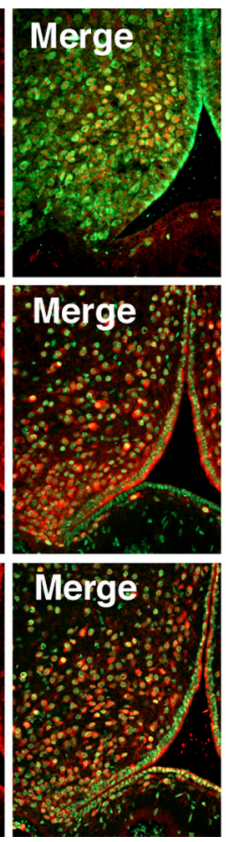
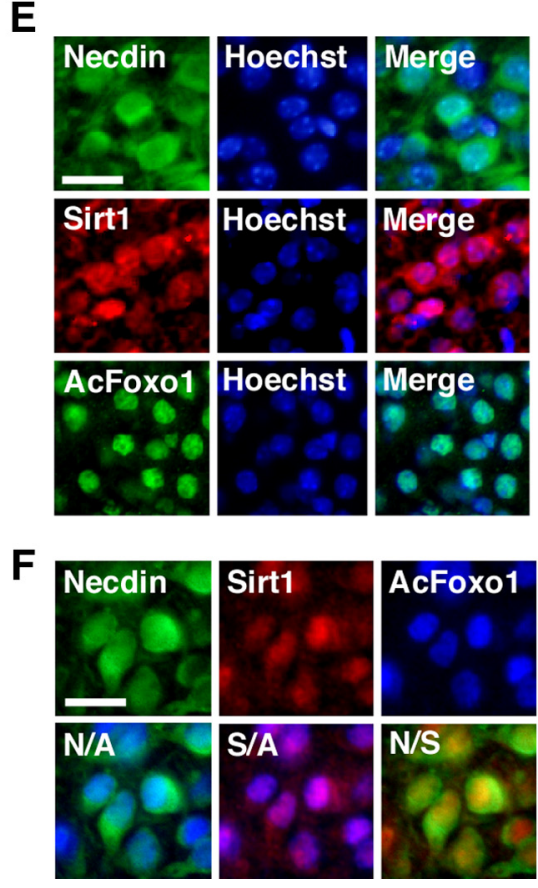

Figure 1. Necdin, Sirt1, and acetylated Foxo1 are expressed in the hypothalamus. $\boldsymbol{A}, \boldsymbol{B}$, Western blot analysis of Foxo1, necdin, and Sirt1. The discrete brain regions (A) or discrete hypothalamic nuclei $(\boldsymbol{B})$ of P30 mice were dissected. Tissue lysates were immunoblotted with antibodies to Foxo1, necdin, Sirt1, and $\gamma$-tubulin ( $\gamma$-Tub). CX, Cortex; HC, hippocampus; TH, thalamus; HT, hypothalamus; (B, cerebellum; BS, brainstem; PT, pituitary gland. Molecular sizes are reported in kilodaltons. C, D, Double-immunostaining for necdin and Sirt1 (top panels); acetylated Foxo1 (AcFox01) and necdin (middle panels); or AcFox01 and Sirt1 (bottom panels). Forebrain sections prepared from mice at P28 -P30 were double-immunostained for necdin, Sirt1, and AcFoxo1, and two images were merged. Hypothalamic areas near the PVN $(\boldsymbol{C})$ and ARC (D) are shown. 3V, Third ventricle. $\boldsymbol{E}$, Subcellular localization. Images of necdin, Sirt1, and AcFoxo1 in the ARC were merged with the nuclear marker Hoechst 33342 for subcellular localization. $F$, Triple-immunostaining for necdin, Sirt1, and AcFoxo1. Images of necdin (N), Sirt1 (S), AcFoxo1 (A), in the ARC were merged (N/A, S/A, N/S). Scale bars: $C, D, 50 \mu \mathrm{m} ; \boldsymbol{E}, \boldsymbol{F}, 10 \mu \mathrm{m}$.

gctaggtgcgactac-3'); NPY (forward, 5' -caagagatccagccctgaga-3'; reverse, $5^{\prime}$-ctagtggtggcatgcattgg- $\left.3^{\prime}\right) ; P O M C$ (forward, $5^{\prime}$-ctcaccacggagagcaacct$3^{\prime}$; reverse, $5^{\prime}$-ccagcggaagtgacccatga- $\left.3^{\prime}\right)$; TRH (forward, $5^{\prime}$-tcgtgctaactggtatcccc- $3^{\prime}$; reverse, $5^{\prime}$-cccaaatctcccctctcttc- $3^{\prime}$ ); and $N d n$ (forward, $5^{\prime}$-aggacctgagcgaccctaac- $3^{\prime}$; reverse, $5^{\prime}$-tgctgcaggattttagggtcaac- $\left.3^{\prime}\right)$. RTPCR products were quantified with LightCycler FastStart DNA MasterPLUS SYBR Green I (Roche Diagnostics) in a LightCycler instrument. Melting curves were analyzed to confirm a single species of each PCR product. Gapdh cDNA was used as an internal standard to quantify the relative expression of each cDNA.

Hormone assays. Mouse blood samples were left at $37^{\circ} \mathrm{C}$ for $1 \mathrm{~h}$ to allow clotting and were centrifuged at $2300 \times g$ for $20 \mathrm{~min}$ at $4^{\circ} \mathrm{C}$ to obtain the serum. Serum levels of thyroid stimulating hormone (TSH), thyroxin (T4), and triiodothyronin (T3) were measured using ELISA kits for rat TSH (AKRTS-010; Shibayagi), T4 (ERKR7014; Endocrine Technologies), and T3 (ERKR7013; Endocrine Technologies), respectively. To 
A
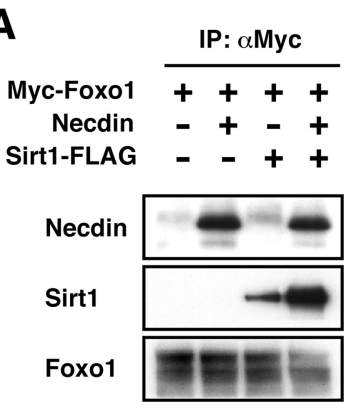

Lane $\begin{array}{llll}1 & 2 & 3 & 4\end{array}$
B
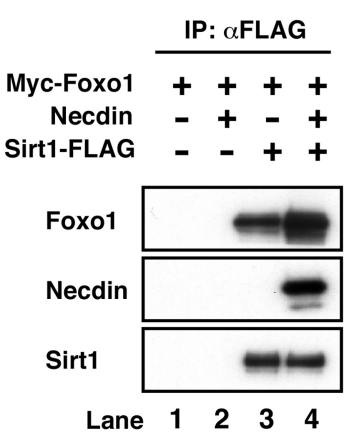

C
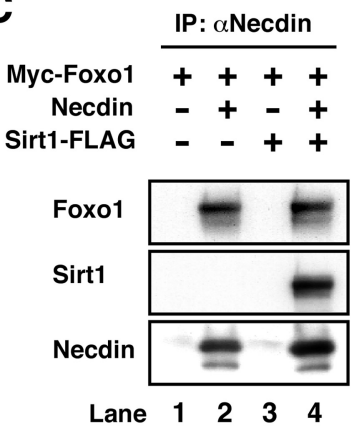

D

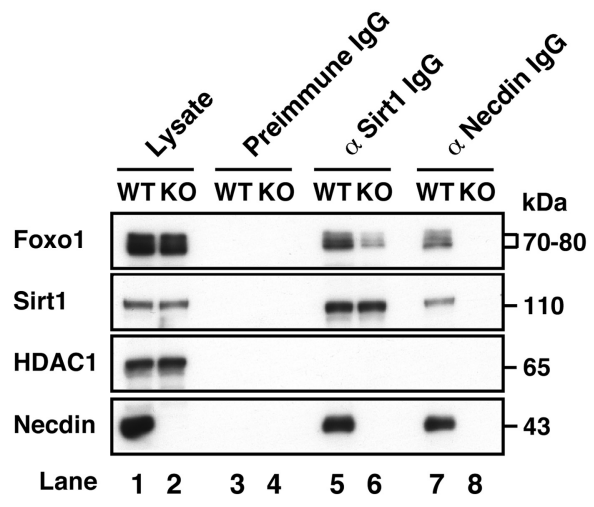

E

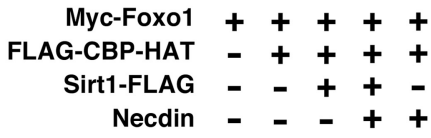

IB: $\alpha$ AcFoxo1

IP: $\alpha$ Myc

IB: $\alpha$ FLAG

IP: $\alpha$ Myc

IB: $\alpha$ Necdin

IB: $\alpha$ Myc

IB: $\alpha$ FLAG

IB: $\alpha$ FLAG

IB: $\alpha$ Necdin

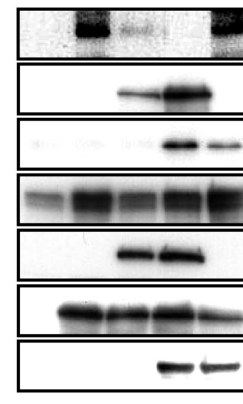

(kDa)

AcFoxo1

(85)

$\checkmark$ Sirt1

(120)

4 Necdin

(43)

Fox01

(85)

$\checkmark$ Sirt1

(120)

$\checkmark$ CBP-HAT

(75)

(43)

Lane $\quad \begin{array}{lllll}1 & 2 & 3 & 4 & 5\end{array}$

Figure 2. Necdin interacts with both Sirt1 and Foxo1 to promote Sirt1-mediated Foxo 1 deacetylation. $\boldsymbol{A}-\boldsymbol{C}$, Coimmunoprecipitation assay. HEK293A cells were transfected with expression vectors for Myc-Fox01, necdin, and Sirt1-FLAG, and the lysates $(200 \mu \mathrm{g})$ were immunoprecipitated (IP) with antibodies to Myc $(\alpha \mathrm{Myc})(\boldsymbol{A})$, FLAG $(\alpha \mathrm{FLAG})(\boldsymbol{B})$, or necdin $(\alpha$ Necdin) $(\boldsymbol{C})$ and detected with antibodies to necdin (Necdin) and FLAG (Sirt1) (A); Myc (Foxo1) and necdin (Necdin) (B); or Myc (Fox01) and FLAG (Sirt1) (C). Immunoprecipitated proteins were shown on the bottom panels ( $\boldsymbol{A}-\boldsymbol{C}$ ). D, Immunoprecipitation of the endogenous complex containing necdin, Sirt1, and Fox01. Hypothalamic lysates (1 mg) from P30 mice were immunoprecipitated with the antibodies GS1 ( $\alpha$ Sirt1 lgG), GN1 ( $\alpha$ Necdin lgG), or preimmune lgG and detected with antibodies against Foxo1, Sirt1, HDAC1, and necdin. WT, $\mathrm{Ndn}^{+/+} ; \mathrm{KO}, \mathrm{Ndn}{ }^{+\mathrm{m} /-\mathrm{p}}$. Lysate, Hypothalamic lysate (10 $\left.\mu \mathrm{g}\right)$. E, Foxo1 acetylation assay. HEK293A cells were transfected with expression vectors for Myc-Foxo1, FLAG-CBP-HAT, Sirt1-FLAG, and necdin. Cell lysates were immunoblotted (IB) with anti-acetyl-Foxo1 antibody ( $\alpha$ AcFox01) (top) for Foxo1 acetylation. For protein interaction assay, cell lysates $(200 \mu \mathrm{g})$ were immunoprecipitated with anti-Myc antibody and immunoblotted with antibodies to FLAG (second panel down) and necdin (third panel down). The expressed proteins (10 $\mu \mathrm{g}$ ) are shown in the bottom four panels.

induce a hyperthyroid state, 4-week-old male mice were injected intraperitoneally with PBS containing T3 $(0.2 \mathrm{mg} / \mathrm{kg}$ ) (Sigma-Aldrich) or PBS alone (control), and hypothalamic tissue blocks and the sera were collected $24 \mathrm{~h}$ later. To induce a hypothyroid state, 4-week-old male mice were given drinking water containing $0.05 \%(\mathrm{w} / \mathrm{v})$ propylthiouracil (PTU) (Sigma-Aldrich) for $21 \mathrm{~d}$ (Pantos et al., 2003). Mice were killed between 5:00 P.M. and 7:00 P.M. to collect the tissue and blood samples.

Metabolic monitoring. $\mathrm{O}_{2}$ consumption and $\mathrm{CO}_{2}$ production of 4 - and 12-week-old male mice were measured with an Oxymax apparatus (Columbus Instrument), and the locomotor activity was with an ACTIMO-100 (Bio Research Center) (Kim et al., 2012). Data were collected every $18 \mathrm{~min}$ for each mouse over a period of $3 \mathrm{~d}$. Core body temperature was measured with BDT-100 (Bio Research Center) at 1:00 P.M. and 7:00 P.M.

Statistical tests. Statistical significance was tested using an unpaired Student's $t$ test or one-way ANOVA followed by the Tukey's post hoc test. A significance of $p<0.05$ was required for rejection of the null hypothesis.

\section{Results}

Necdin, Sirt1, and acetylated Foxo1 are colocalized in a subpopulation of hypothalamic neurons

To study the regulatory role of necdin in Sirt1-mediated Foxo1 deacetylation during hypothalamic development, we used male mice during the early postweaning period, when hypothalamic orexigenic neurocircuitry including ARC neurons is expected to be yet incomplete (Luquet et al., 2005). We first examined the expression levels of Foxo1, necdin, and Sirt1 in discrete brain regions and pituitary gland of P30 mice by Western blotting (Fig. $1 A$ ). The Foxol protein with major $80 \mathrm{kDa}$ and minor $70 \mathrm{kDa}$ bands was detected at high levels in the neocortex, hippocampus, and cerebellum. The level of the $43 \mathrm{kDa}$ necdin protein was the highest in the hypothalamus. The $110 \mathrm{kDa}$ Sirtl band was strongly expressed in the cerebellum and pituitary gland in agreement with the previous report (Ramadori et al., 2008). We next analyzed the expression levels of Foxo1, necdin, and Sirt1 in discrete hypothalamic nuclei (Fig. $1 \mathrm{~B}$ ). We dissected the hypothalamic block into smaller blocks containing the paraventricular nucleus (PVN), lateral hypothalamus (LH), dorsomedial nucleus $(\mathrm{DMN})$, ventromedial nucleus (VMN), and ARC. Although these proteins were expressed at similar levels in hypothalamic nuclei, expression levels of necdin and Sirt1 were the highest in the ARC. We then immunohistochemically examined the expression of these proteins in the PVN and ARC of P28-P30 mice. Necdin was localized in the nucleus and cytoplasm of hypothalamic neurons (Fig. 1C-E). Sirt1 was mainly localized in the nucleus, and most of the Sirt1-immunopositive cells overlapped with necdin-immunopositive cells. We were able to detect acetylated Foxol by immunohistochemistry. Acetylated Foxolwas colocalized with necdin and Sirt1 in the nucleus of PVN and ARC cells. Acetylated Foxol was detected almost exclusively in the nucleus (Fig. $1 E$, bottom). Triple-immunostaining analysis re- 
vealed that these three proteins were colocalized in the nucleus of the ARC neurons (Fig. $1 F$ ). These results suggest that necdin, Sirt1, and acetylated Foxo1 are coexpressed in the ARC neurons at this developmental stage.

\section{Necdin promotes Foxo1 deacetylation by facilitating the association with Sirt 1 and Foxo1}

We next examined whether necdin binds to both Foxo 1 and Sirt1 to form a ternary complex. Coimmunoprecipitation assay using transfected HEK293A cells revealed that Foxol bound to necdin in the absence or presence of Sirt1 (Fig. 2A, top, lanes 2, 4). Foxo1 interacted with Sirt1, and coexpression of necdin increased the amount of Sirt 1 bound to Foxol (Fig. $2 A$, middle, lanes 3,4). Necdin also increased the amount of Foxol bound to Sirt1 when precipitated with Sirt1 (Fig. $2 B$, top, lanes $3,4)$. Conversely, Foxol and Sirtl were coprecipitated with necdin (Fig. 2C, top, middle, lanes 2,4$)$. These data suggest that necdin interacts with both Sirtl and Foxo1 to form a stable nuclear complex.

We then examined whether the complex containing necdin, Sirt1, and Foxo1 was endogenously present in the hypothalamic extract prepared from P30 mice (Fig. 2D). Foxol in the $\mathrm{Ndn}{ }^{+/+}$extract was coprecipitated with Sirt1, whereas the amount of Foxol bound to Sirtl in the $N d n^{+\mathrm{m} /-\mathrm{p}}$ hypothalamic extract was markedly reduced (Fig. $2 D$, top, lanes 5, 6 ), suggesting that necdin facilitates the interaction between Foxol and Sirt1. Furthermore, Foxol was coprecipitated with necdin in the $N d n^{+/+}$extract, but not in the $N d n^{+\mathrm{m} /-\mathrm{p}}$ extract (Fig. 2D, top, lanes 7,8 ). In contrast, necdin and Sirt1 failed to interact with $\mathrm{HDAC1}$, a class I histone deacetylase (Fig. $2 \mathrm{D}$, middle bottom). These data suggest that endogenous necdin forms a stable complex with Sirt1 and Foxo1 in the hypothalamus.

We investigated the effect of necdin on Sirt1-mediated Foxo1 deacetylation by Western blot analysis using antiacetylated Foxol antibody (Fig. 2E). Foxo1 was hyperacetylated by the histone acetyltransferase domain of CBP (CBP-HAT) (Fig. 2 E, top, lane 2). In this assay, Sirt 1 reduced the acetylation level of Foxo1, and coexpression of necdin promoted Foxoldeacetylation (Fig. 2E, top, lanes 3, 4). In the absence of Sirt1, necdin failed to deacetylate Foxo1 (Fig. 2E, top, lane 5), suggesting that necdin itself has no deacetylase activity. Necdin increased the amount of Sirt1 bound to Foxol (Fig. 2E, second panel down, lanes 3, 4). These results suggest that necdin promotes Sirt1-mediated Foxo1 deacetylation by facilitating the association between Foxol and Sirtl.

\section{Necdin suppresses Foxo1-dependent transcriptional activity via Sirt1}

We then examined the effect of necdin on Foxo1-dependent transcriptional activity using the luciferase reporter linked to the promoter containing three copies of the insulin response sequence, a Foxo1-binding motif. Sirt1 suppressed Foxo1-dependent transcription in a dose-dependent manner (Fig. 3A). Necdin also strongly repressed Foxo1-dependent transcription in a dose-dependent
B

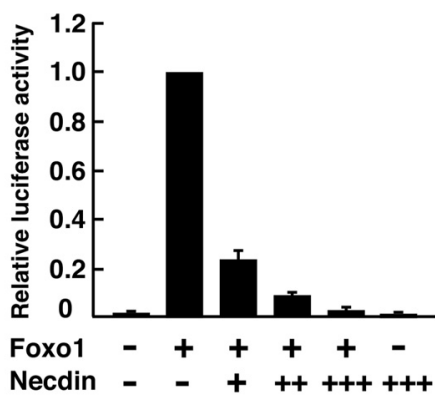

D

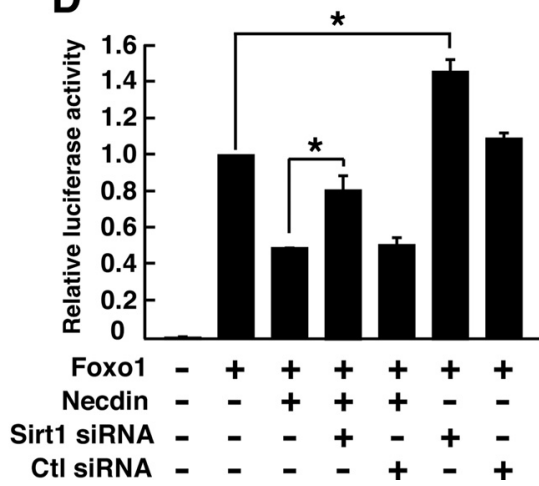

Figure 3. Necdin and Sirt1 suppress Fox01-dependent transcription. A-C, Transcriptional suppression by necdin and Sirt1.

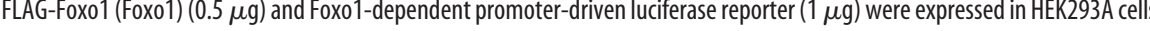
added in the reporter assay in combination with the vectors for Fox01 and necdin $(0.2 \mu \mathrm{g})$. Transfection efficiency was normalized to the Renilla luciferase activity $(\boldsymbol{A}-\boldsymbol{D} ;$ mean $\pm \mathrm{SEM} ; n=3) .{ }^{*} p<0.01$.

manner (Fig. 3B). Furthermore, Sirtl and necdin suppressed the Foxol activity in an additive manner (Fig. 3C). To examine whether necdin suppresses Foxo1-dependent transcription via Sirt1mediated deacetylation, endogenous Sirtl expression was downregulated by cotransfection with Sirt1 siRNA. Sirt1 siRNA, but not control siRNA, relieved necdin-mediated Foxol suppression (Fig. 3D), indicating that necdin-dependent suppression is mediated by endogenous Sirt 1 to a significant extent. In addition, Sirt1 siRNA significantly enhanced Foxo1-dependent transcriptional activation. These data implicate that the acetylated form of Foxol is transcriptionally more active than its deacetylated form.

\section{Necdin deficiency increases Foxol acetylation in the hypothalamus}

We next analyzed the acetylated Foxol levels in the ARC of P28 mice by fluorescence microphotometry (Fig. 4). In $\mathrm{Ndn}{ }^{+\mathrm{m} /-\mathrm{p}}$ mice, the signal intensity of acetylated Foxo1 was significantly increased in the hypothalamic ARC, VMN, and PVN, but not in the cerebral cortex and hippocampal dentate gyrus (Fig. 4A-C). The acetylated Foxol levels in the ARC, VMN, and PVN of $N d n^{+\mathrm{m} /-\mathrm{p}}$ mice were $2.3,1.7$, and 1.4 times, respectively, those of the $N d n^{+/+}$mice (Fig. $4 D$ ). We then quantified acetylated Foxo 1 in the hypothalamic extract by Western blotting and subsequent densitometry (Fig. $4 E$ ). The acetylated Foxol levels (normalized to the Foxo1 levels) were significantly increased in the hypothal-

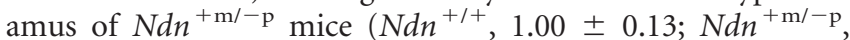
$2.11 \pm 0.06 ; n=3$ for each group; $p=0.002)$. These data suggest that endogenous necdin regulates acetylated Foxo 1 levels in hypothalamic neurons. 
A
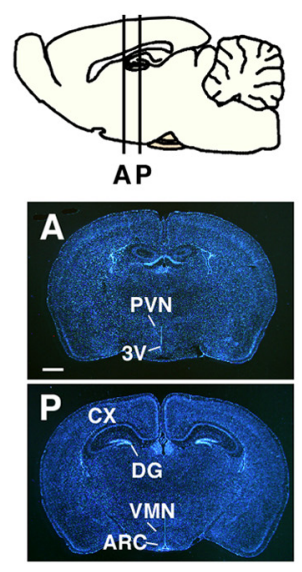

C
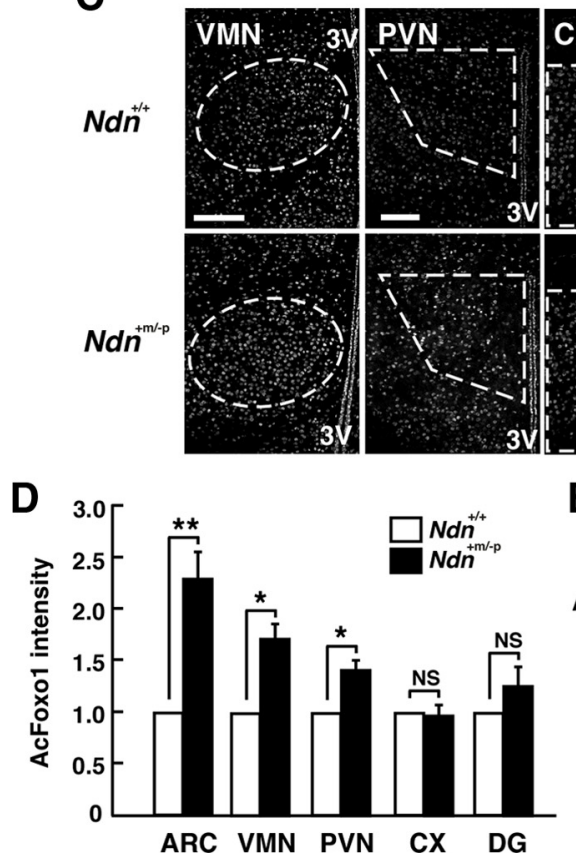

B
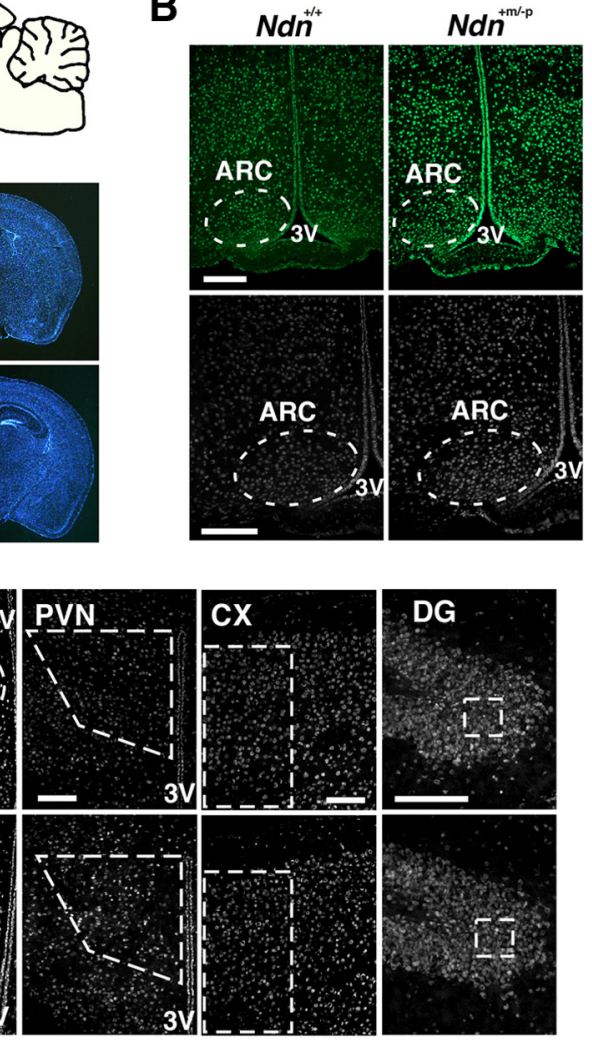
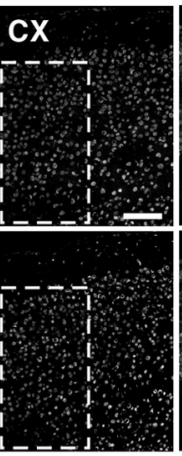

E

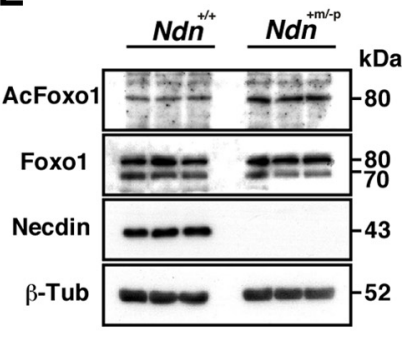

Figure 4. Necdin deficiency increases Fox01 acetylation in the hypothalamus. $\boldsymbol{A}$, Brain regions analyzed by fluorescence microphotometry. Frozen sections ( $12 \mu \mathrm{m}$ thickness) from P28 mice were stained with Hoechst 33342 for orientation. A, Anterior brain section; $P$, posterior brain section; $C X$, cerebral cortex; DG, dentate gyrus; $3 \mathrm{~V}$, third ventricle. Scale bar, $1 \mathrm{~mm}$. $\boldsymbol{B}$, Immunostaining for acetylated Fox01. Frozen hypothalamic sections of $\mathrm{Ndn}^{+/+}$and $\mathrm{Ndn}{ }^{+\mathrm{m} /-\mathrm{p}}$ P28 mice were immunostained for acetyl-Fox01. Immunohistochemical images (top panels) and representative images analyzed by fluorescence microphotometry (bottom panels) are presented. Analyzed ARC areas are outlined (dashed ellipses). C, Brain region images used for fluorescence microphotometry. Representative images of acetylated Foxo1 in four brain areas (VMN, PVN, CX, and DG) are shown. Fluorescence intensities inside the dashed lines were measured by microphotometry. Scale bars: $B, C, 50 \mu \mathrm{m}$. D, Quantification of acetylated Fox01 immunoreactivity. Intensities of acetylated Foxo1 in the ARC $(n=4)$, VMN $(n=3), \operatorname{PVN}(n=4), C X(n=4)$, and DG $(n=$ 4) were quantified by fluorescence microphotometry (mean $\pm \mathrm{SEM}$ ). ${ }^{*} p<0.01$; ${ }^{* *} p<0.005$. NS, Not significant $(p \geq 0.05)$. $\boldsymbol{E}$, Western blot analysis of acetylated Fox01. Hypothalamic lysates $(10 \mu \mathrm{g})$ were immunoblotted with antibodies to acetylated Fox01 (AcFox01), Fox01, necdin, and $\beta$-tubulin ( $\beta$-Tub). Quantitative data are in Results.

\section{Expression of Agrp and Npy increases in}

necdin-deficient hypothalamus

We next investigated whether endogenous necdin and Sirt1 bind to the promoter of Agrp, a Foxo1-dependent gene (Kitamura et al., 2006). ChIP assay revealed that necdin, Sirt1, and Foxol bound to the Agrp promoter (Fig. 5A), suggesting that necdin and Sirtl control the transcriptional activity of Foxol in hypothalamic AGRP neurons. We then analyzed the expression levels of the Foxo1regulated genes Agrp and Npy in vivo in the hypothalamus. Quantitative RT-PCR analysis revealed that expression of Agrp and Npy in $N d n^{+\mathrm{m} /-\mathrm{p}}$ mice was significantly increased 1.7 and 1.4 times the $\mathrm{Ndn}{ }^{+/+}$level, respectively (Fig. $5 B$ ), whereas expression levels of

Pomc, which is transcriptionally suppressed by Foxo1 (Kitamura et al., 2006), did not differ significantly between $\mathrm{Ndn}{ }^{+/+}$and $N d n^{+\mathrm{m} /-\mathrm{p}}$ mice. These results imply that endogenous necdin suppresses Agrp and Npy expression in the ARC neurons in vivo.

\section{Necdin deficiency causes endocrine dysfunction characteristic of hypothalamic hypothyroidism} Activation of AGRP and NPY neurons increase food intake and body weight (Barsh and Schwartz, 2002). Thus, we measured daily food intake and body weight in $N d n^{+\mathrm{m} /-\mathrm{p}}$ mice during the P28-P31 period. However, $N d n^{+\mathrm{m} /-\mathrm{p}}$ mice exhibited no significant increase in daily food intake $\left(N d n^{+/+}, 4.65 \pm 0.10 \mathrm{~g}, n=11 ; N d n^{+\mathrm{m} /-\mathrm{p}}\right.$, $4.72 \pm 0.15 \mathrm{~g}, n=10 ; p \geq 0.05)$ or body weight at P31 $\left(\mathrm{Ndn}{ }^{+/+}, 25.0 \pm 1.0 \mathrm{~g}, n=\right.$ 13; $N d n^{+\mathrm{m} /-\mathrm{p}}, 23.9 \pm 1.0 \mathrm{~g}, n=16 ; p \geq$ 0.05). Because the AGRP/NPY neurons suppress TRH neurons in the PVN (Barsh and Schwartz, 2002; Fekete et al., 2002), we then analyzed the activity of the HPT axis in $N d n^{+\mathrm{m} /-\mathrm{p}}$ mice. We first examined the expression levels of Foxo1, necdin, and Sirtl in the PVN, pituitary, and thyroid gland by Western blotting (Fig. $6 A)$. These proteins were highly expressed in the PVN, whereas Foxol and necdin were expressed at very low or undetectable levels in the thyroid gland. The pituitary gland expressed low levels of the 70 $\mathrm{kDa}$ Foxol and necdin proteins but the highest level of the Sirt1 protein.

We then analyzed the expression levels of TRH mRNA in various hypothalamic nuclei of $N d n^{+\mathrm{m} /-\mathrm{p}}$ mice (Fig. $6 \mathrm{~B}$ ). Although there was no significant difference in the TRH mRNA level of the total hypothalamus between $\mathrm{Ndn} n^{+/+}$and $N d n^{+\mathrm{m} /-\mathrm{p}}$ mice, the TRH mRNA level was significantly decreased only in the PVN of $N d n^{+\mathrm{m} /-\mathrm{p}}$ mice (50\% reduction). The TRH mRNA level in the ARC was low in $\mathrm{Ndn}^{+/+}$mice but increased in $\mathrm{Ndn}{ }^{+\mathrm{m} /-\mathrm{p}}$ mice. Western blot analysis revealed that the proTRH level in the hypothalamus was significantly decreased in $N d n^{+\mathrm{m} /-\mathrm{p}}$ mice (43\% reduction; $N d n^{+/+}$, $1.00 \pm 0.10 ; N d n^{+\mathrm{m} /-\mathrm{p}}, 0.57 \pm 0.02 ; n=3$ for each group; $p=$ 0.012 ; normalized to the $\beta$-tubulin levels) (Fig. $6 \mathrm{C}$ ). The reduction of TRH expression in the hypothalamus of $N d n^{+\mathrm{m} /-\mathrm{p}}$ mice suggested that necdin deficiency causes dysfunction of the HPT axis. Thus, we measured the serum levels of TSH, T4, and T3, and found that those of TSH, T4, and T3 significantly decreased in $N d n^{+\mathrm{m} /-\mathrm{p}}$ mice $(30,25$, and $67 \%$ reduction, respectively) (Fig. $6 D)$, suggesting that endogenous necdin normally upregulates the HPT axis. As hypothermia is a common symptom of hypothyroidism, we measured rectal temperatures of mice during the behaviorally inactive (1:00 P.M.) and active (7:00 P.M.) periods. We found that $N d n^{+\mathrm{m} /-\mathrm{p}}$ mice $(n=16)$ had significantly lower 
A
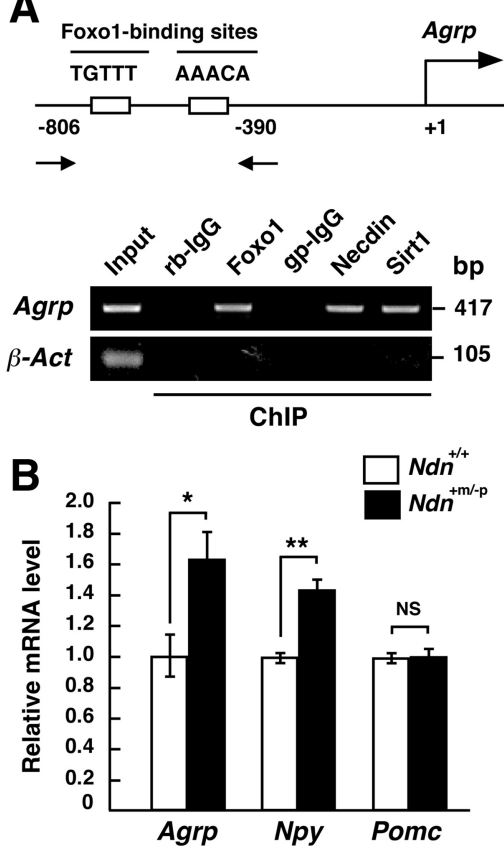

Figure 5. Expression of Agrp and Npy is increased in necdin-deficient hypothalamus. $A$, ChIP assay. A diagram represents Fox01 binding sites on Agrp promoter and PCR primer positions (arrows). Hypothalamic extracts prepared from P30 mice were cross-linked with formaldehyde and immunoprecipitated with lgGs to Foxo1, necdin, Sirt1, rabbit lgG (rb-lgG, control of Fox01), and guinea pig lgG (gp-lgG, control of necdin and Sirt1). Input DNA (Input) and total immunoprecipitated DNA (ChIP) were analyzed by PCR for $A g r p$ and $\beta$-actin ( $\beta$-Act) promoter sequences. Fragment sizes are in base pairs. B, Quantitative RT-PCR. CDNA (10 ng) reverse transcribed from hypothalamic RNA $(2 \mu \mathrm{g})$ was amplified by real-time PCR using primers for Agrp, Npy, and Pomc (mean $\pm \mathrm{SEM}, n=3$ ) ${ }^{*} p<0.05$; ${ }^{* *} p<0.01$. NS, Not significant $(p \geq 0.05 ; n=3)$. $n=7 ; p \geq 0.05$; RQ: $N d n^{+/+}, 0.967 \pm 0.005, n=8 ; N d n^{+\mathrm{m} /-\mathrm{p}}$, $0.961 \pm 0.005, n=7 ; p \geq 0.05$; locomotor activity: $\mathrm{Ndn}^{+/+}$, $3065 \pm 544$ counts, $n=8 ; N d n^{+\mathrm{m} /-\mathrm{p}}, 2790 \pm 584$ counts, $n=7 ; p \geq$ $0.05)$.

Thyroid hormone regulates hypothalamic levels of necdin, acetylated Foxo1, and neuropeptide mRNAs

To examine whether T3 affects the necdin-mediated Foxol deacetylation and neuropeptide gene expression, 4-week-old male mice were treated with T3 for $24 \mathrm{~h}$ (hyperthyroid state) and the anti-thyroid agent PTU for $21 \mathrm{~d}$ (hypothyroid state). We first analyzed the serum levels of T3 and TSH to examine the effects of these treatments. Serum T3 levels were significantly increased by T3 (control, $2.95 \pm 0.19 \mathrm{ng} / \mathrm{ml}$; T3, $9.84 \pm 0.59 \mathrm{ng} / \mathrm{ml} ; p<0.005$, $n=3$ for each group) and decreased by PTU (control, $2.25 \pm 0.34$ $\mathrm{ng} / \mathrm{ml}, n=6$; PTU, $0.72 \pm 0.16 \mathrm{ng} / \mathrm{ml}, n=7 ; p<0.005)$. Conversely, serum TSH levels were decreased by T3 (control $17.0 \pm$ $0.6 \mathrm{ng} / \mathrm{ml}, n=6$; T3, $12.5 \pm 0.6 \mathrm{ng} / \mathrm{ml}, n=7 ; p<0.001)$ and increased by PTU (control, $13.4 \pm 0.3 \mathrm{ng} / \mathrm{ml}, n=6$; PTU, $19.0 \pm$ $0.8 \mathrm{ng} / \mathrm{ml}, n=7 ; p<0.005)$. In $N d n^{+\mathrm{m} /-\mathrm{p}}$ mice, T3 failed to reduce the serum TSH level (control, $11.7 \pm 0.3 \mathrm{ng} / \mathrm{ml}, n=4$; T3, $12.1 \pm 0.3 \mathrm{ng} / \mathrm{ml}, n=6 ; p \geq 0.05)$. Rectal temperatures were increased by T3 (control, $37.4 \pm 0.2^{\circ} \mathrm{C}$; T3, $38.8 \pm 0.1^{\circ} \mathrm{C} ; n=3$ for each group; $p<0.005$ ) and decreased by PTU (control, $37.3 \pm 1.0^{\circ} \mathrm{C}, n=9$; PTU, $\left.36.4 \pm 0.1^{\circ} \mathrm{C}, n=10 ; p<0.005\right)$.

We then analyzed the expression levels of necdin, acetylated Foxo1, and neuropeptides under these conditions. T3 significantly reduced the necdin protein levels in the hypothalamus ( $45 \%$ reduction) but not in the cortex (Fig. $7 A, B$ ), whereas PTU markedly increased the necdin level in the hypothalamus $(2.8$ times the control level) but not in the cortex (Fig. 7C,D). These body temperatures than $N d n^{+/+}$mice $(n=13)\left(N d n^{+/+}, 36.8 \pm 0.1^{\circ} \mathrm{C} ; \mathrm{Ndn} n^{+\mathrm{m} /}\right.$ $-\mathrm{p}, 35.0 \pm 0.1^{\circ} \mathrm{C}$ at 1:00 P.M.; $p<0.01$; $N d n^{+/+}, 37.0 \pm 0.3^{\circ} \mathrm{C} ; N_{d n}{ }^{+\mathrm{m} /-} \mathrm{p}, 35.4 \pm$ $0.2^{\circ} \mathrm{C}$ at 7:00 P.M.; $\left.p<0.01\right)$. However, $N d n^{+\mathrm{m} /-\mathrm{p}}$ mice showed no abnormal core body temperatures at other developmental stages including the adult stage (data not shown).

We analyzed the whole-body energy expenditure and found no significant difference in $\mathrm{O}_{2}$ consumption, $\mathrm{CO}_{2}$ production, respiratory quotient (RQ), or locomotor activity between $\mathrm{Ndn}{ }^{+/+}$and $\mathrm{Ndn}{ }^{+\mathrm{m} /-\mathrm{p}}$ mice at 4 weeks of age $\left(\mathrm{O}_{2}\right.$ consumption: $N d n^{+/+}, 79.5 \pm 3.5 \mathrm{~L} / \mathrm{kg} / 24 \mathrm{~h}$, $n=8 ; N d n^{+\mathrm{m} /-\mathrm{p}}, 83.4 \pm 3.1 \mathrm{~L} / \mathrm{kg} / 24 \mathrm{~h}$, $n=8 ; p \geq 0.05 ; \mathrm{CO}_{2}$ production: $N d n^{+/+}, 77.0 \pm 3.0 \mathrm{~L} / \mathrm{kg} / 24 \mathrm{~h}, n=8$; $N d n^{+\mathrm{m} /-\mathrm{p}}, 80.6 \pm 3.0 \mathrm{~L} / \mathrm{kg} / 24 \mathrm{~h}, n=8$; $p \geq 0.05$; RQ: $N d n^{+/+}, 0.970 \pm 0.008, n=$ $8 ; N d n^{+\mathrm{m} /-\mathrm{p}}, 0.966 \pm 0.008, n=8 ; p \geq$ 0.05; locomotor activity: $N d n^{+/+}, 3065 \pm$ 351 counts, $n=8 ; N d n^{+\mathrm{m} /-\mathrm{p}}, 3497 \pm$ 1054 counts, $n=7 ; p \geq 0.05)$ and at 12 weeks of age $\left(\mathrm{O}_{2}\right.$ consumption: $\mathrm{Ndn} n^{+/+}$, $53.0 \pm 1.5 \mathrm{~L} / \mathrm{kg} / 24 \mathrm{~h}, n=8 ; N d n^{+\mathrm{m} /-\mathrm{p}}$, $53.2 \pm 1.8 \mathrm{~L} / \mathrm{kg} / 24 \mathrm{~h}, n=7 ; p \geq 0.05 ; \mathrm{CO}_{2}$ production: $\mathrm{Ndn}{ }^{+/+}, 51.3 \pm 1.5 \mathrm{~L} / \mathrm{kg} / 24$ $\mathrm{h}, n=8 ; N d n^{+\mathrm{m} /-\mathrm{p}}, 51.1 \pm 1.9 \mathrm{~L} / \mathrm{kg} / 24 \mathrm{~h}$,
A

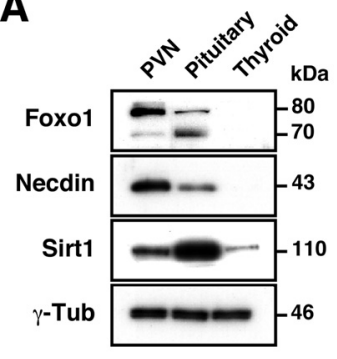

B

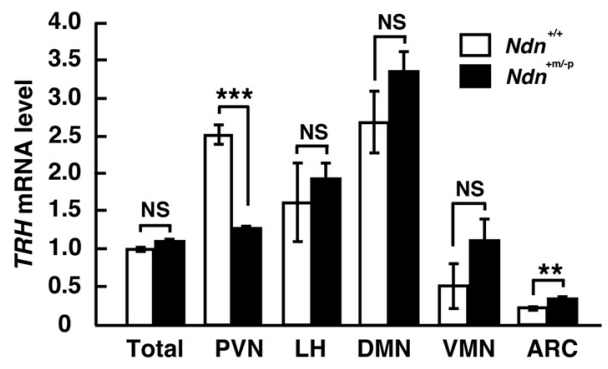

C

D
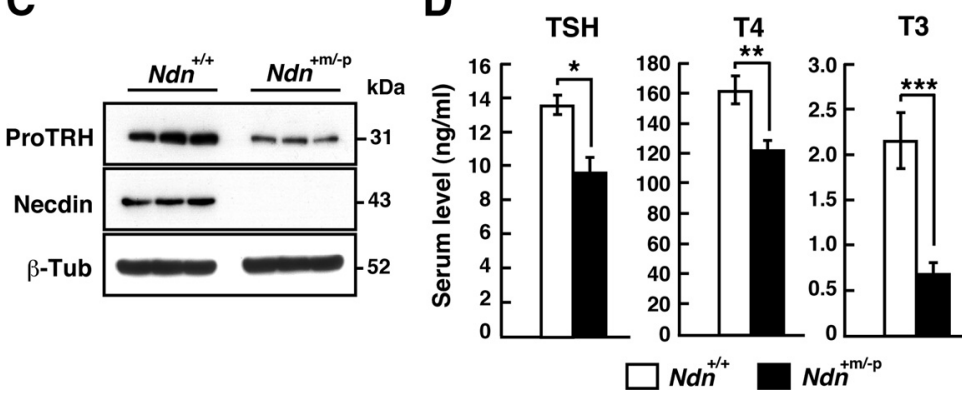

Figure 6. Necdin deficiency causes HPT axis dysfunction. $\boldsymbol{A}$, Western blot analysis. The PVN, pituitary, and thyroid were prepared from P30 mice. Tissue lysates were immunoblotted with antibodies to Foxo1, necdin, Sirt1, and $\gamma$-tubulin ( $\gamma$-Tub). $\boldsymbol{B}$ TRH mRNA levels in hypothalamic nuclei. Five hypothalamic nuclei were dissected from hypothalamic blocks (Total) of $\mathrm{Ndn}{ }^{+1+}$ and $N d n^{+m /-p}$ P30 mice. CDNA was amplified by real-time PCR using the primers for $T R H(n=3)$. C, Western blot analysis. Lysates were immunoblotted with antibodies to TRH precursor protein (ProTRH), necdin, and $\beta$-tubulin ( $\beta$-Tub). D, Serum hormone levels. Mice were maintained in $12 \mathrm{~h}$ light/dark cycle (light on at 8:00 A.M.), and blood samples were collected between 5:00 P.M. and 7:00 P.M. Sera were prepared from $\mathrm{Ndn}^{+/+}(n=4)$ and $\mathrm{Ndn}{ }^{+\mathrm{m} /-\mathrm{p}}$ mice $(n=8)$, and TSH, T4, and T3 were assayed (mean \pm SEM). ${ }^{*} p<0.05 ;{ }^{* *} p<0.01 ;{ }^{* * *} p<0.001$. 

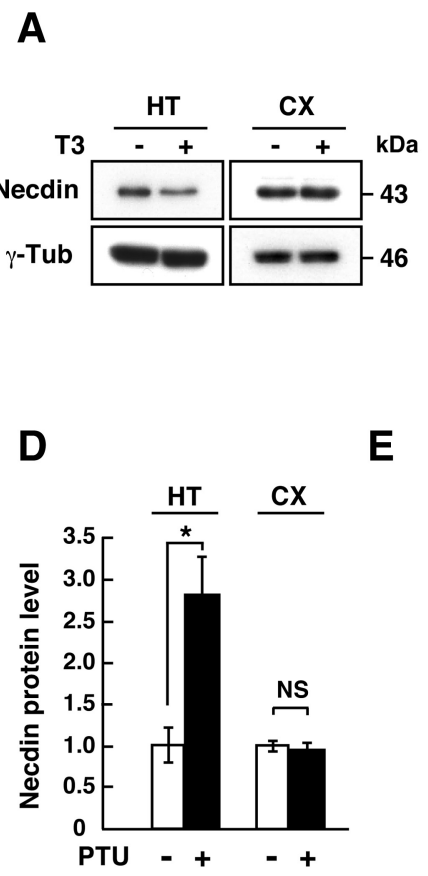

G

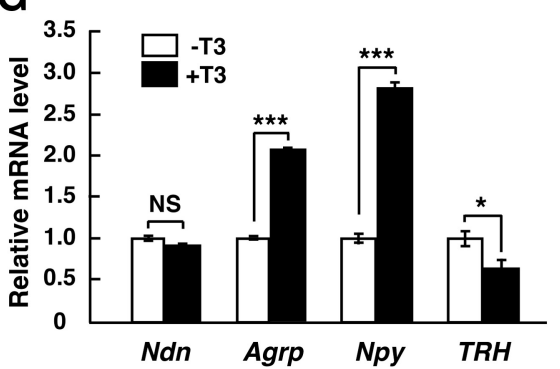

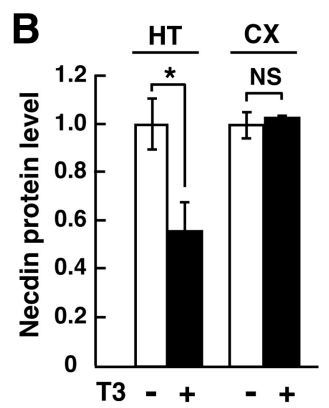

E

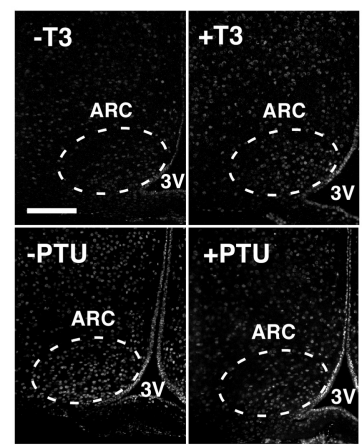

H

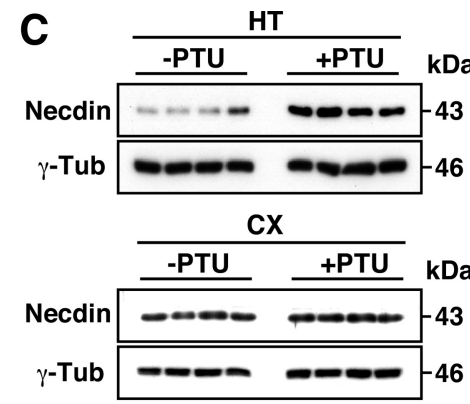

$\mathbf{F}$

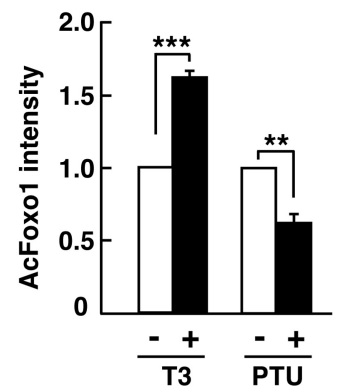

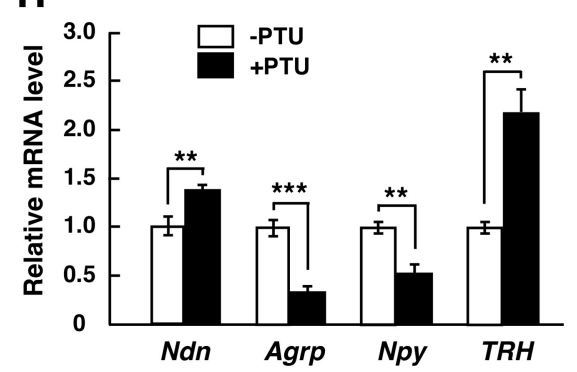

Figure 7. Thyroid hormone regulates necdin expression, Foxo1 acetylation, and neuropeptide gene expression in the hypothalamus. $A, B$, Regulation of necdin protein levels by $T 3$. Hypothalamic (HT) and cortical (CX) tissues of P29 mice were prepared $24 \mathrm{~h}$ after T3 injection, and lysates were analyzed by Western blotting using antibodies to necdin and $\gamma$-tubulin $(\gamma$-Tub) $(\boldsymbol{A})$. The necdin levels were quantified by densitometry and normalized to the $\gamma$-tubulin levels $(\boldsymbol{B})(n=3)$. $\boldsymbol{C}, \boldsymbol{D}$, Regulation of necdin protein levels by PTU. Proteins (10 $\mu \mathrm{g})$ in the tissues prepared from mice treated without ( - PTU) and with PTU (+PTU) for $21 \mathrm{~d}$ were analyzed by Western blotting $(\boldsymbol{C})$ and quantified $(\boldsymbol{D})(n=4)$. $\boldsymbol{E}, \boldsymbol{F}$, Acetylated Foxo 1 levels. Hypothalamic cryosections were prepared from mice treated with T3 or PTU and immunostained for acetylated Fox01. The fluorescent intensities inside the dashed lines $(\boldsymbol{E})$ were analyzed by fluorescence microphotometry $(\boldsymbol{F})(n=3)$. 3V, Third ventricle. Scale bar, $50 \mu \mathrm{m} . \boldsymbol{G}, \boldsymbol{H}$, Hypothalamic levels of mRNAs encoding Ndn, Agrp, Npy, and TRH. CDNA was prepared from mice treated with T3 $(\boldsymbol{G})$ and PTU $(\boldsymbol{H})$, and analyzed by real-time PCR $\left(n=3\right.$; except $n=6$ for TRH). $\boldsymbol{B}, \mathbf{D}, \boldsymbol{F}-\boldsymbol{H}$, mean \pm SEM. ${ }^{*} p<0.05 ;{ }^{* *} p<0.01 ;{ }^{* * *} p<0.001$. NS, Not significant $(p \geq 0.05)$.

results suggest that thyroid hormone efficiently regulates the hypothalamic necdin expression. Acetylated Foxol levels in the ARC were significantly increased by T3 (1.6 times the control level) and decreased by PTU (38\% reduction) (Fig. $7 E, F)$.

We next analyzed hypothalamic necdin and neuropeptide mRNA levels in these hyperthyroid and hypothyroid states (Fig. $7 G$ ). Although T3 reduced hypothalamic necdin protein levels, there was no appreciable change in the Ndn mRNA level. This discrepancy may be attributable to a delayed recovery or prolonged degradation of the necdin protein $24 \mathrm{~h}$ after acute T3 treatment. T3 significantly increased the Agrp and Npy mRNA levels (2.1 and 2.8 times the control level, respectively), whereas T3 decreased the Agrp and Npy mRNA levels in $N d n^{+\mathrm{m} /-\mathrm{p}}$ mice (Agrp mRNA: control, $1.00 \pm 0.02 ; \mathrm{T} 3,0.64 \pm 0.02 ; p<0.01 ; N p y$ mRNA: control, $1.00 \pm 0.01$; T3, $0.80 \pm 0.06 ; p<0.01 ; n=3$ for each group), indicating that endogenous necdin is indispensable for T3-stimulated Agrp/Npy expression. T3 decreased the TRH mRNA levels in both $N d n^{+/+}$(36\% reduction) (Fig. 7G) and $\mathrm{Ndn}{ }^{+\mathrm{m} /-\mathrm{p}}$ mice (38\% reduction; control, $1.13 \pm 0.07 ; \mathrm{T} 3,0.70 \pm$
$0.03 ; n=6$ for each group; $p<0.05$ ), suggesting that T3 regulates TRH gene expression via a necdin-independent negativefeedback pathway. Because T3 affected orexigenic Agrp and Npy mRNA expression, we measured food intake in $\mathrm{Ndn}{ }^{+/+}$and $N d n^{+\mathrm{m} /-\mathrm{p}}$ mice before and after single T3 administration. Food intake of $\mathrm{Ndn}^{+/+}$mice did not differ before and after T3 treatment (before T3, $4.92 \pm 0.22 \mathrm{~g} / 24 \mathrm{~h}$; after T3, $4.82 \pm 0.09 \mathrm{~g} / 24 \mathrm{~h}$; $n=9$ for each group; $p \geq 0.05$ ), but significantly decreased in $\mathrm{Ndn}{ }^{+\mathrm{m} /-\mathrm{p}}$ mice (before T3, $4.91 \pm 0.29 \mathrm{~g} / 24 \mathrm{~h}$; after T3, $4.07 \pm$ $0.19 \mathrm{~g} / 24 \mathrm{~h} ; n=6$ for each group; $p<0.05$ ), indicating that T3 affects food intake only in the absence of necdin. In contrast to the T3-induced changes in neuropeptide gene expression, PTU significantly decreased the Agrp and Npy mRNA levels to $33 \%$ and $53 \%$, respectively, of the control levels and increased the expression levels of necdin and TRH mRNAs (1.4 and 2.2 times the control levels, respectively) (Fig. $7 \mathrm{H}$ ). Although PTU significantly reduced food intake (control, $4.63 \pm 0.18$ g/24 h, $n=9$; PTU, $4.19 \pm 0.12 \mathrm{~g} / 24 \mathrm{~h}, n=10 ; p<0.05$; measured on the last day of treatment), there was no signifi- 

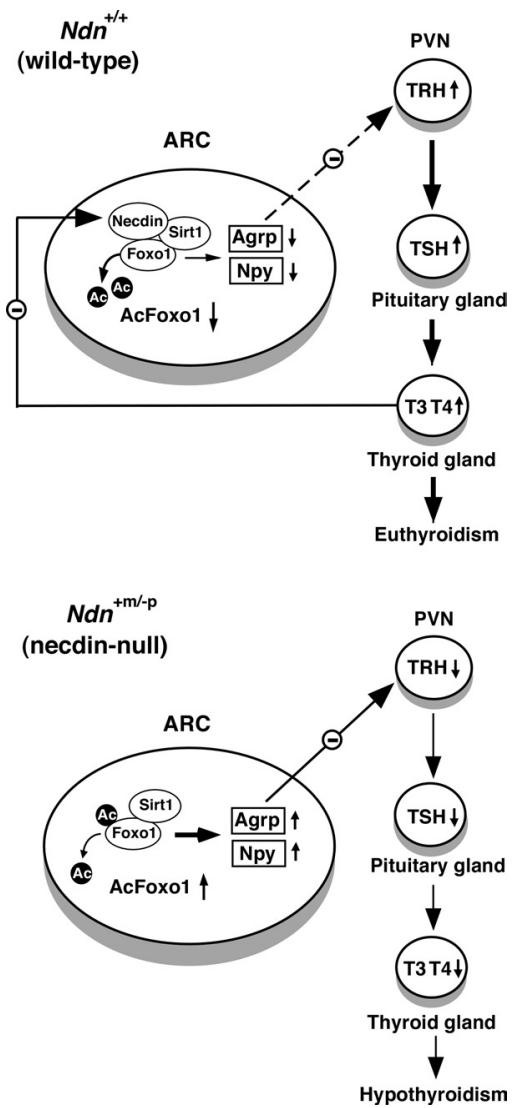

Figure 8. A model for necdin-mediated Foxo1 acetylation and neuropeptide gene expression in HPT axis modulation. In $\mathrm{Ndn}^{+/+}$mice, necdin promotes Sirt1-mediated Foxo1 deacetylation, and a reduction in the acetylated Fox01 (AcFox01) level suppresses Agrp/Npy gene expression in the ARC to activate the HPT axis. T3 exerts an inhibitory effect on this ARC system. $\ln N d n^{+m /-p}$ mice, acetylated Foxo 1 and Agrp/Npy mRNA expression are increased to suppress the HPT axis. See Discussion for details.

cant difference in body weight between control and PTUtreated mice (control, $37.5 \pm 1.0 \mathrm{~g}, n=9$; PTU, $35.8 \pm 0.7 \mathrm{~g}$, $n=10 ; p \geq 0.05)$.

\section{Discussion}

On the basis of the present data, we propose that necdin controls the acetylation level of hypothalamic Foxol via Sirt1 in the ARC neurons and modulates the function of the HPT axis (Fig. 8). Necdin forms a stable complex with Sirt1 and Foxol, promotes Sirt1-mediated Foxol deacetylation, and suppresses Foxo1dependent transcription. Thus, necdin maintains low levels of acetylated Foxo 1 and suppresses Foxo1-dependent Agrp/Npy expression in the ARC neurons. In the absence of necdin, Foxo1 acetylation increases in these neurons, in which Agrp/Npy expression is also upregulated. Because AGRP/NPY neurons in the ARC exert inhibitory effects on TRH neurons in the PVN (Fekete et al., 2002), the increased Agrp/Npy expression due to necdin deficiency may inhibit TRH neurons. This idea is supported by the findings that significant reduction of the TRH mRNA level occurred in the PVN of necdin-deficient mice (Fig. 6B). Accordingly, it is suggested that necdin activates the HPT axis via the ARC neurons, whereas its deficiency suppresses the HPT axis leading to hypothalamic hypothyroidism.

The present study has shown that $\mathrm{T} 3$ exerts negative regulatory effects on the necdin-Sirt1-Foxol system in the ARC. T3induced hyperthyroidism and PTU-induced hypothyroidism caused hypothalamic responses similar to those under necdindeficient and excessive conditions, respectively, as T3 increased acetylated Foxo1 and Agrp/Npy mRNA levels, whereas PTU decreased acetylated Foxol and Agrp/Npy mRNAs. These responses may be attributed to the T3-induced $N d n$ suppression in the ARC. Because Ndn transcription is negatively regulated by T3 (Nygård et al., 2006), it is possible that T3 directly suppresses hypothalamic $N d n$ expression. However, acute T3 administration reduced the necdin protein level (Fig. $7 A, B$ ) but had little or no effect on the $N d n$ mRNA level (Fig. $7 G$ ). On the other hand, chronic PTU administration increased the expression levels of both the necdin protein and mRNA (Fig. 7D, H). Thus, hypothalamic $N d n$ expression is likely controlled by T3 in a durationdependent manner.

It has been previously reported that Sirt1 and its activator, Resveratrol, stimulate Foxo1-dependent transcription via Foxo1 deacetylation (Daitoku et al., 2004; Frescas et al., 2005). Sirt1 enhances the transcriptional activity of Foxol on the promoter containing the insulin response sequence linked to the luciferase reporter in stably transfected HEK293 (FK1) cells (Daitoku et al., 2004). In the present study, we used the same promoter-reporter and found that necdin and Sirt1 suppress Foxo1-dependent transcription via Foxo1 deacetylation in transiently transfected HEK293A cells, in which Sirt1 siRNA enhanced the Foxo1-dependent transcriptional activation and relieved necdin-dependent transcriptional suppression (Fig. 3D). This discrepancy can be attributable to the difference between stably and transiently transfected cell systems. Transcriptional activities in the stably transfected cells can be influenced by cis-elements and epigenetic states (e.g., methylated $\mathrm{CpG}$ clusters) near inserted sites of the reporter genes. Our data are consistent with previous findings that Sirt1 represses transcriptional activities of Foxo3a and Foxol (Motta et al., 2004; Yang et al., 2005), and coexpression of p300 enhances their transcriptional activities (Motta et al., 2004; Perrot and Rechler, 2005). In accordance with these data, Foxol acetylation, AGRP, and NPY were significantly increased in vivo in necdin-deficient mice. Acetylation of the Foxo proteins controls expression of downstream genes involved in various cellular functions in context-dependent manners (Brunet et al., 2004; Motta et al., 2004). Thus, the ARC AGRP/NPY neurons may represent a specific group of hypothalamic neurons in which acetylated Foxol induces transcriptional activation of their own genes. Although necdin, Sirt1, and Foxo1 are expressed in various hypothalamic nuclei (Fig. $1 B$ ), the TRH mRNA level was significantly reduced only in the PVN of necdin-null mice (Fig. $6 \mathrm{~B}$ ). If the necdin-Sirt1-Foxol complex or necdin directly controls $T R H$ gene transcription, $T R H$ expression in these hypothalamic nuclei should also be affected by necdin deficiency. Thus, it is most likely that necdin indirectly stimulates TRH expression in the PVN via the ARC neurons.

There are close similarities between Foxo1 and p53 in their acetylation processes controlled by the necdin-Sirtl complex in neurons. Necdin forms a stable complex with both Sirt1 and p53, promotes p53 deacetylation, and dampens the proapoptotic activity of p53 in response to DNA damage or environmental stresses (Hasegawa and Yoshikawa, 2008). Similarly, necdin forms a stable complex with Sirt1 and Foxo1, and promotes Sirt1mediated Foxo1 deacetylation. Both Foxo and p53 undergo prompt acetylation in neurons by acetyltransferases in response to cellular stresses (Brunet et al., 2004; Hasegawa and Yoshikawa, 2008). Under necdin-deficient conditions, acetylation levels of neocortical p53 and hypothalamic Foxo1 are significantly elevated (Hasegawa and Yoshikawa, 2008; present study). Thus, we 
propose that endogenous necdin promotes Sirt1-mediated deacetylation of these proteins and protects neurons from detrimental stresses such as oxygen stress and DNA damage.

The present study has also shown that endogenous necdinSirtl complex efficiently deacetylates Foxol and inhibits Agrp/ Npy expression in the ARC neurons under physiological conditions. The ternary complex of necdin, Sirt1, and Foxol may bind to the Agrp and Npy promoters and suppresses Foxo1mediated transcriptional activities (Fig. 5A). Although enhanced synthesis of the neuropeptides AGRP and NPY is expected to increase food intake under physiological conditions (Barsh and Schwartz, 2002), we observed no significant increase in ad libitum food intake or body weight gain in necdin-deficient mice during the early postweaning period. It has previously been reported that Agrp-deficient or Agrp/Npy double-knock-out mice exhibit no abnormal phenotype in food intake or body weight gain (Qian et al., 2002). However, selective ablation of AGRP neurons induced by cell type-specific expression of a diphtheria toxin receptor results in acute anorexia in adult mice (Gropp et al., 2005). Furthermore, the ablation of NPY/AGRP neurons causes rapid starvation in adults, but its effect is minimal in the neonatal period (Luquet et al., 2005). Thus, the absence of hyperphagia in necdindeficient mice during the early postweaning period may be because the orexigenic neurocircuitry containing ARC AGRP/NPY neurons is not yet complete.

Increased AGRP/NPY synthesis in necdin-deficient mice is expected to reduce energy expenditure (Barsh and Schwartz, 2002). The ARC AGRP/NPY neurons project their axons to the PVN-TRH neurons and negatively modulate their activities. In accordance with this idea, we found a reduction of the TRH mRNA level in the PVN and proTRH protein in necdin-null mice, in which serum TSH, T4, and T3 levels were significantly reduced, suggesting that necdin deficiency leads to hypothalamic hypothyroidism (Fig. $6 B-D$ ). Although energy expenditure is expected to decrease in hypothyroidism, we found that necdin-null mice showed neither altered expression of energy metabolismrelated genes in the skeletal muscle and liver at 5 weeks of age (Fujiwara et al., 2012) nor reduced net energy expenditure at 4 and 12 weeks of age (present study). We speculate that the abnormalities seen in necdin-deficient hypothalamic ARC neurons during the early postweaning period are normalized or compensated by remodeling the neurocircuitry during development, leading to normal energy expenditure.

PWS is caused by the lack of paternal expression of several contiguous genes including NDN located in chromosome 15q11q13 region, which has syntenic homology with mouse chromosome 7C region (Jay et al., 1997; MacDonald and Wevrick, 1997). Mice having the paternal deletion of this region exhibit neonatal lethality on the C57BL/6 background (Gabriel et al., 1999). Ndndeficient mice are also neonatally lethal on the C57BL/6 background (Gérard et al., 1999; Muscatelli et al., 2000). Because hypothalamic neurocircuitry involved in energy homeostasis develops during the postnatal period (Bouret et al., 2004), we used ICR mice, which exhibit no lethality throughout the lifetime $(\mathrm{Ku}-$ wako et al., 2005), and found that necdin deficiency caused dysfunction of the HPT axis during the juvenile period. Intriguingly, it has recently been reported that thyroid axis dysfunction is frequently present in PWS during the first two years of life (Vaiani et al., 2010). This clinical report suggests that hypothalamic hypothyroidism is a common feature in infants with PWS. Because both T3 and TRH play important roles in brain development as well as in systemic energy homeostasis (Anderson, 2001; Lechan and Fekete, 2006), it is possible that dysfunction of the HPT axis caused by necdin deficiency contributes to abnormal brain development, which may lead to behavioral abnormalities. Our present data may also provide insights into the significance of necdin in the pathogeneses of neuroendocrine and behavioral abnormalities in PWS.

\section{References}

Accili D, Arden KC (2004) FoxOs at the crossroads of cellular metabolism, differentiation, and transformation. Cell 117:421-426.

Aizawa T, Maruyama K, Kondo H, Yoshikawa K (1992) Expression of necdin, an embryonal carcinoma-derived nuclear protein, in developing mouse brain. Brain Res Dev Brain Res 68:265-274.

Anderson GW (2001) Thyroid hormones and the brain. Front Neuroendocrinol 22:1-17.

Barsh GS, Schwartz MW (2002) Genetic approaches to studying energy balance: perception and integration. Nat Rev Genet 3:589-600.

Bouret SG, Draper SJ, Simerly RB (2004) Trophic action of leptin on hypothalamic neurons that regulate feeding. Science 304:108-110.

Brunet A, Sweeney LB, Sturgill JF, Chua KF, Greer PL, Lin Y, Tran H, Ross SE, Mostoslavsky R, Cohen HY, Hu LS, Cheng HL, Jedrychowski MP, Gygi SP, Sinclair DA, Alt FW, Greenberg ME (2004) Stress-dependent regulation of FOXO transcription factors by the SIRT1 deacetylase. Science 303:2011-2015.

Daitoku H, Hatta M, Matsuzaki H, Aratani S, Ohshima T, Miyagishi M, Nakajima T, Fukamizu A (2004) Silent information regulator 2 potentiates Foxo1-mediated transcription through its deacetylase activity. Proc Natl Acad Sci U S A 101:10042-10047.

Dryden S, Frankish HM, Wang Q, Pickavance L, Williams G (1996) The serotonergic agent fluoxetine reduces neuropeptide $\mathrm{Y}$ levels and neuropeptide $\mathrm{Y}$ secretion in the hypothalamus of lean and obese rats. Neuroscience 72:557-566

Fekete C, Sarkar S, Rand WM, Harney JW, Emerson CH, Bianco AC, Lechan RM (2002) Agouti-related protein (AGRP) has a central inhibitory action on the hypothalamic-pituitary-thyroid (HPT) axis; comparisons between the effect of AGRP and neuropeptide Y on energy homeostasis and the HPT axis. Endocrinology 143:3846-3853.

Frescas D, Valenti L, Accili D (2005) Nuclear trapping of the forkhead transcription factor FoxO1 via Sirt-dependent deacetylation promotes expression of glucogenetic genes. J Biol Chem 280:20589-20595.

Fujiwara K, Hasegawa K, Ohkumo T, Miyoshi H, Tseng YH, Yoshikawa K (2012) Necdin controls proliferation of white adipocyte progenitor cells. PLoS One 7:e30948.

Gabriel JM, Merchant M, Ohta T, Ji Y, Caldwell RG, Ramsey MJ, Tucker JD, Longnecker R, Nicholls RD (1999) A transgene insertion creating a heritable chromosome deletion mouse model of Prader-Willi and Angelman syndromes. Proc Natl Acad Sci U S A 96:9258-9263.

Gérard M, Hernandez L, Wevrick R, Stewart CL (1999) Disruption of the mouse necdin gene results in early post-natal lethality. Nat Genet 23:199-202.

Gropp E, Shanabrough M, Borok E, Xu AW, Janoschek R, Buch T, Plum L, Balthasar N, Hampel B, Waisman A, Barsh GS, Horvath TL, Brüning JC (2005) Agouti-related peptide-expressing neurons are mandatory for feeding. Nat Neurosci 8:1289-1291.

Haigis MC, Sinclair DA (2010) Mammalian sirtuins: biological insights and disease relevance. Annu Rev Pathol 5:253-295.

Hasegawa K, Yoshikawa K (2008) Necdin regulates p53 acetylation via Sirtuin 1 to modulate DNA damage response in cortical neurons. J Neurosci 28:8772-8784.

Jay P, Rougeulle C, Massacrier A, Moncla A, Mattei MG, Malzac P, Roëckel N, Taviaux S, Lefranc JL, Cau P, Berta P, Lalande M, Muscatelli F (1997) The human necdin gene, NDN, is maternally imprinted and located in the Prader-Willi syndrome chromosomal region. Nat Genet 17:357-361.

Kim HJ, Kobayashi M, Sasaki T, Kikuchi O, Amano K, Kitazumi T, Lee YS, Yokota-Hashimoto H, Susanti VY, Kitamura YI, Nakae J, Kitamura T (2012) Overexpression of FoxO1 in the hypothalamus and pancreas causes obesity and glucose intolerance. Endocrinology 153:659-671.

Kim MS, Pak YK, Jang PG, Namkoong C, Choi YS, Won JC, Kim KS, Kim SW, Kim HS, Park JY, Kim YB, Lee KU (2006) Role of hypothalamic Foxo1 in the regulation of food intake and energy homeostasis. Nat Neurosci 9:901-906.

Kitamura T, Feng Y, Kitamura YI, Chua SC Jr, Xu AW, Barsh GS, Rossetti L, 
Accili D (2006) Forkhead protein FoxO1 mediates Agrp-dependent effects of leptin on food intake. Nat Med 12:534-540.

Kuwajima T, Nishimura I, Yoshikawa K (2006) Necdin promotes GABAergic neuron differentiation in cooperation with Dlx homeodomain proteins. J Neurosci 26:5383-5392.

Kuwako K, Hosokawa A, Nishimura I, Uetsuki T, Yamada M, Nada S, Okada M, Yoshikawa K (2005) Disruption of the paternal necdin gene diminishes TrkA signaling for sensory neuron survival. J Neurosci 25:7090-7099.

Lechan RM, Fekete C (2006) The TRH neuron: a hypothalamic integrator of energy metabolism. Prog Brain Res 153:209-235.

Lee TI, Johnstone SE, Young RA (2006) Chromatin immunoprecipitation and microarray-based analysis of protein location. Nat Protoc 1:729-748.

Luquet S, Perez FA, Hnasko TS, Palmiter RD (2005) NPY/AgRP neurons are essential for feeding in adult mice but can be ablated in neonates. Science 310:683-685.

MacDonald HR, Wevrick R (1997) The necdin gene is deleted in PraderWilli syndrome and is imprinted in human and mouse. Hum Mol Genet 6:1873-1878.

Maruyama K, Usami M, Aizawa T, Yoshikawa K (1991) A novel brainspecific mRNA encoding nuclear protein (necdin) expressed in neurally differentiated embryonal carcinoma cells. Biochem Biophys Res Commun 178:291-296.

Motta MC, Divecha N, Lemieux M, Kamel C, Chen D, Gu W, Bultsma Y, McBurney M, Guarente L (2004) Mammalian SIRT1 represses forkhead transcription factors. Cell 116:551-563.

Muscatelli F, Abrous DN, Massacrier A, Boccaccio I, Le Moal M, Cau P, Cremer H (2000) Disruption of the mouse Necdin gene results in hypothalamic and behavioral alterations reminiscent of the human PraderWilli syndrome. Hum Mol Genet 9:3101-3110.

Niinobe M, Koyama K, Yoshikawa K (2000) Cellular and subcellular localization of necdin in fetal and adult mouse brain. Dev Neurosci 22:310-319.

Nygård M, Becker N, Demeneix B, Pettersson K, Bondesson M (2006) Thyroid hormone-mediated negative transcriptional regulation of Necdin expression. J Mol Endocrinol 36:517-530.
Pantos C, Malliopoulou V, Mourouzis I, Sfakianoudis K, Tzeis S, Doumba P, Xinaris C, Cokkinos AD, Carageorgiou H, Varonos DD, Cokkinos DV (2003) Propylthiouracil-induced hypothyroidism is associated with increased tolerance of the isolated rat heart to ischaemia-reperfusion. J Endocrinol 178:427-435.

Perrot V, Rechler MM (2005) The coactivator p300 directly acetylates the forkhead transcription factor Foxol and stimulates Foxol-induced transcription. Mol Endocrinol 19:2283-2298.

Qian S, Chen H, Weingarth D, Trumbauer ME, Novi DE, Guan X, Yu H, Shen Z, Feng Y, Frazier E, Chen A, Camacho RE, Shearman LP, Gopal-Truter S, MacNeil DJ, Van der Ploeg LH, Marsh DJ (2002) Neither agouti-related protein nor neuropeptide $\mathrm{Y}$ is critically required for the regulation of energy homeostasis in mice. Mol Cell Biol 22:5027-5035.

Ramadori G, Lee CE, Bookout AL, Lee S, Williams KW, Anderson J, Elmquist JK, Coppari R (2008) Brain SIRT1: anatomical distribution and regulation by energy availability. J Neurosci 28:9989-9996.

Sasaki T, Kim HJ, Kobayashi M, Kitamura YI, Yokota-Hashimoto H, Shiuchi T, Minokoshi Y, Kitamura T (2010) Induction of hypothalamic Sirt1 leads to cessation of feeding via agouti-related peptide. Endocrinology 151:2556-2566.

Takazaki R, Nishimura I, Yoshikawa K (2002) Necdin is required for terminal differentiation and survival of primary dorsal root ganglion neurons. Exp Cell Res 277:220-232.

Uetsuki T, Takagi K, Sugiura H, Yoshikawa K (1996) Structure and expression of the mouse necdin gene. Identification of a postmitotic neuronrestrictive core promoter. J Biol Chem 271:918-924.

Vaiani E, Herzovich V, Chaler E, Chertkoff L, Rivarola MA, Torrado M, Belgorosky A (2010) Thyroid axis dysfunction in patients with PraderWilli syndrome during the first 2 years of life. Clin Endocrinol (Oxf) 73:546-550.

van der Horst A, Burgering BM (2007) Stressing the role of FoxO proteins in lifespan and disease. Nat Rev Mol Cell Biol 8:440-450.

Yang Y, Hou H, Haller EM, Nicosia SV, Bai W (2005) Suppression of FOXO1 activity by FHL2 through SIRT1-mediated deacetylation. EMBO J 24:1021-1032. 